\title{
Studi Osifikasi dan Morfokinetik Berudu Katak Rana catesbeiana Shaw. dengan Alizarin Red
}

\author{
The Ossification Study and Tadpoles Morphokinetic of \\ Rana catesbeiana Shaw. with Alizarin Red
}

\author{
Suryanti ${ }^{1 *}$, Hari Santoso, ${ }^{2 * *}$, Ratna Djuniwati Lisminingsih ${ }^{3}$ \\ ${ }^{123}$ Jurusan Biologi Fakultas Matematika dan Ilmu Pengetahuan Alam Universitas Islam Malang, Indonesia. \\ Email: suri97yanti@gmail.com
}

\begin{abstract}
ABSTRAK
Berudu merupakan salah satu fase dari metamorfosis katak. Berudu katak hidup di air, sebelum ekstremitas anterior dan ekstremitas posterior terbentuk. Pertumbuhan ekstremitas posterior dibarengi dengan kalsifikasi dan ekstremitas anterior diikuti dengan memendeknya ekor berudu. Tujuan penelitian ini untuk mengetahui osifikasi dan morfokinetik berudu bagian ekstremitas posterior, ekstremitas anterior dan penyusutan ekor berudu. Berudu katak tidak memiliki kaki dan bergerak menggunakan ekor. Metoda penelitian menggunakan Teknik kuantitatif deskriptif. Berudu yang digunakan adalah hasil metamorfosis usia 4 bulan. Tulang yang telah mengalami osifikasi ditandai dengan adanya perubahan warna pada tulang menjadi merah keunguan. Berudu katak mengalami perkembangan dalam dua fase, meliputi fase embrio dan fase larva. Terbentuknya kaki belakang terjadi pada tahap 26-30, dilanjutkan dengan terbentuknya jari kaki (toe development) pada tahap 31-37. Ekstremitas anterior yang terosifikasi : os humerus, os radio-ulna, os metacarpal dan os falangs, ekstremitas posterior : os femur, os tibiofibula, os tarsal dan os metatarsal.
\end{abstract}

Kata Kunci : Berudu, Osifikasi, Ekstremitas

\begin{abstract}
Tadpole is a phase of frog metamorphosis. The frog tadpoles live in water, before the anterior extremities and posterior extremities are formed. Posterior limb growth is accompanied by calcifications and the anterior extremity followed by shortening of the tadpole tail. The aim research was to determine the ossification and morphokinetics of tadpoles in the posterior extremities, anterior limbs and tadpole tail shrinkage. The frog tadpoles do not have legs and move using tails. The research method uses descriptive quantitative techniques. The tadpoles were used a 4-month-old metamorphosis result. The bones have happened ossification that are marked by a change in the color of the bone to purplish red. The frog tadpoles develop in two phases, including the embryonic phase and the larval phase. The formation of hind limbs occurs in stages of 26-30, followed by toe development in stages of 31-37. The anterior extremities are corroded: the humerus os, the radio -ulna os, the os metacarpal and the falangs os, the posterior limb: the femoral os, the tibio-fibular os, the tarsal os and the metatarsal os.
\end{abstract}

Keywords: Tadpoles, Ossification, extremities

\footnotetext{
$\left.{ }^{*}\right)$ Suryanti, Jurusan Biologi FMIPA UNISMA, Jl. MT Haryono 193, Malang65144 Tlp. 081333505157 email: suri97yanti@gmail.com

${ }^{* *}$ Drs. H Hari Santoso M. Biomed, Jurusan Biologi FMIPA UNISMA, Jl. MT Haryono 193, Malang65144 Tlp. Telp.082331449560 email: harisantoso.m.biomed@gmail.com
}

Diterima Tanggal 4 Pebruari 2019 - Diterbitkan Tanggal 25 Januari 2020 


\section{Pendahuluan}

Katak lembu atau yang dikenal dengan sebutan Bullfrog di Amerika, termasuk dalam famili Ranidae, spesies Rana catesbeiana. Katak lembu dewasa bisa mencapai ukuran panjang $20 \mathrm{~cm}$ dan berat 750 gram [1]. Selanjutnya, katak lembu mempunyai daya adaptasi yang tinggi terhadap kondisi lingkungan yang kurang baik dan dapat hidup sampai 9 tahun setelah metamorfosis. bull frog (Rana catesbiana Shaw) atau yang biasa di sebut dengan katak lembu adalah salah satu suatu komoditi andalan dari perikanan yang bertujuan untuk ekspor.Katak lembu ini telah terbukti memiliki beberapa kelebihan di antaranya lebih lembut dan jinak, cepat dalam menyesuaikan lingkungan yang buatan walaupun ukurannya lebih besar dari pada katak endemik.Budidaya sudah berkembang sangat baik pada areal Jawa Timur [2].

Peran osifikasi dan morfokinetik pada berudu katak Rana catesbeiana Shaw dalam dunia biologi adalah untuk melihat tahap perkembangan (embriologi) berudu hingga menjadi katak muda (percil) salah satunya dengan metode pewarnaan. Pewarnaan tulang adalah salah satu cara untuk mengetahui perkembangan penulangan (osifikasi) pada tulang. Dalam pembuatan pewarnaan tulang terdapat 2 metode pewarnaan tulang, yaitu : a) pewarna tulang keras, b) pewarna yang digunakan pada pewarnaan tulang umumnya adalah alizarin Red-s. Alizarin Red-s berguna sebagai pendeteksi adanya proses kalsifikasi didaerah tulang yang terwarnai [3]. Alizarin Red-s mampu terserap oleh osteum (tulang keras), bersifat asam memberikan warna merah keunguan pada tulang.Hal ini dikarenakan adalah perbedaan muatan pada alizarin Red-s sebagai pewarna dan osteum sehingga osteum dapat terwarnai [4].

\section{Material dan Metode}

\section{Alat dan Bahan}

Alat-alat yang di gunakan dalam penelitian ini adalah inkubator, alat bedah, mangkuk,tempat spesimen berupa botol, cawan petri, pipet tetes, jangka sorong, dan mikroskop.

Bahan-bahan pada penelitian ini yang di gunakan dalam penelitian adalah berudu katak usia 4 bulan, 4 bulan 5 hari, 4 bulan 10 hari dan 4 bulan 15 hari (setelah metamorfosis), alcohol kadar 95\%, pewarna larutan Alizarin red, penjernih A dalam bentuk larutan, larutan penjernih B, larutan penjernih $\mathrm{C}, \mathrm{KOH} 1 \%$ dalam bentuk larutan, gliserin yang murni, garam fisiologis (larutan), tymol dan aquades.

\section{Metode}

Desain penelitian yang digunakan pada penelitian ini termasuk jenis penelitian kuantitatif.Data yang diperoleh selanjutnya dianalisis secara deskriptif dan statistik.Analisis deskriptif dengan menyajikan gambar dan grafik dilakukan terhadap ukuran panjang ekstremitas pada katak.

\section{Cara Kerja}

Diambil berudu katak Rana catesbeiana Shaw hasil metamorfosis yang masih hidup (berusia 4 bulan), kemudian ukur panjang ekstremitas atas, ekstremitas bawah dan ekornya.Dibius dengan kloroform hingga pingsan. Berudu kemudian dibersihkan dengan menguliti (dibuang kulitnya) dan dibuang isi perutnya, agar tidak dapat mengkontaminasi identifikasi pada tulang yang sudah selesai proses kalsifikasi, kemudian letakkan di mangkuk yang telah diisi garam fisiologis. Berudu kemudian dibilas dan dibersihkan, dimasukkan kedalam botol bening yang sudah diisi alkohol $96 \%$.Berudu direndam pada alkohol $96 \%$ selama 24 jam. Berudu katak dipindahkan ke wadah lain yang sudah di isi dengan larutan $\mathrm{KOH} 1 \%$ dan di diamkan dalam wadah larutan, sampai otot sampai terlihat transparan serta skeletonnya terlihat sangat jelas. Jaringan otot setelah transparan, berudu katak di pindahkan kedalam wadah yang sudah di beri Alizarin red selanjutnya di rendam pada larutan tersebut sampai skeletonnya berwarna merah cukup tua atau berwarna ungu.Selanjutnya berudu katak dipindahkan ke dalam larutan $\mathrm{KOH} \mathrm{1 \% .Berudu} \mathrm{katak} \mathrm{direndam} \mathrm{dalam} \mathrm{larutan} \mathrm{tersebut} \mathrm{agar} \mathrm{jaringan} \mathrm{otot} \mathrm{benar-benar}$ menjadi transparan. Berikut pindahkan kedalam larutan penjernih A dalam waktu 1 jam, kemudian kedalan larutan penjernih $\mathrm{C}$ dan penjernih yang B tiap penjernih selama 1 jam.Berudu katak di 
pindahkan kedalam larutan yang berisi Gliserin yang murni yang sudah diberi dengan tymol.Kemudian ukur panjang kaki yang tumbuh pada berudu menggunakan miksroskop.

Pembuatan larutan penjernih; Larutan pernjernih A : Gliserin (20 bagian), KOH 4\% (3 bagian) dan akuades (77bagian). Larutan penjernih B : Gliserin (50bagian), $\mathrm{KOH} \mathrm{4 \%} \mathrm{(3} \mathrm{bagian),} \mathrm{dan} \mathrm{akuades}$ ( 25 bagian). Larutan penjernih $\mathrm{C}$ : Gliserin ( 75 bagian) dan aquades ( 25 bagian).

Analisis Data: Pada berudu katak usia 4 bulan (hasil metamorfosis) yang telah diwarnai diamati bagian ekstremitas atas,ekstremitas bawah dan ekor yang telah mengalami osifikasi atau kalsifikasi yang ditandai dengan perubahan warna dari bening menjadi merah tua sampai ungu. Tulang yang telah terwarnai kemudian diukur menggunakan jangka sorong dengan ketelitian 0,05 sebagai data pendukung dalam pengamatan.

\section{Hasil dan Diskusi}

\section{Hasil Penelitian}

Osifikasi pada berudu katak Rana catesbeiana Shaw dapat dilihat dari perubahan warna pada tulang. Tulang tersebut akan berubah warna menjadi merah keunguan.

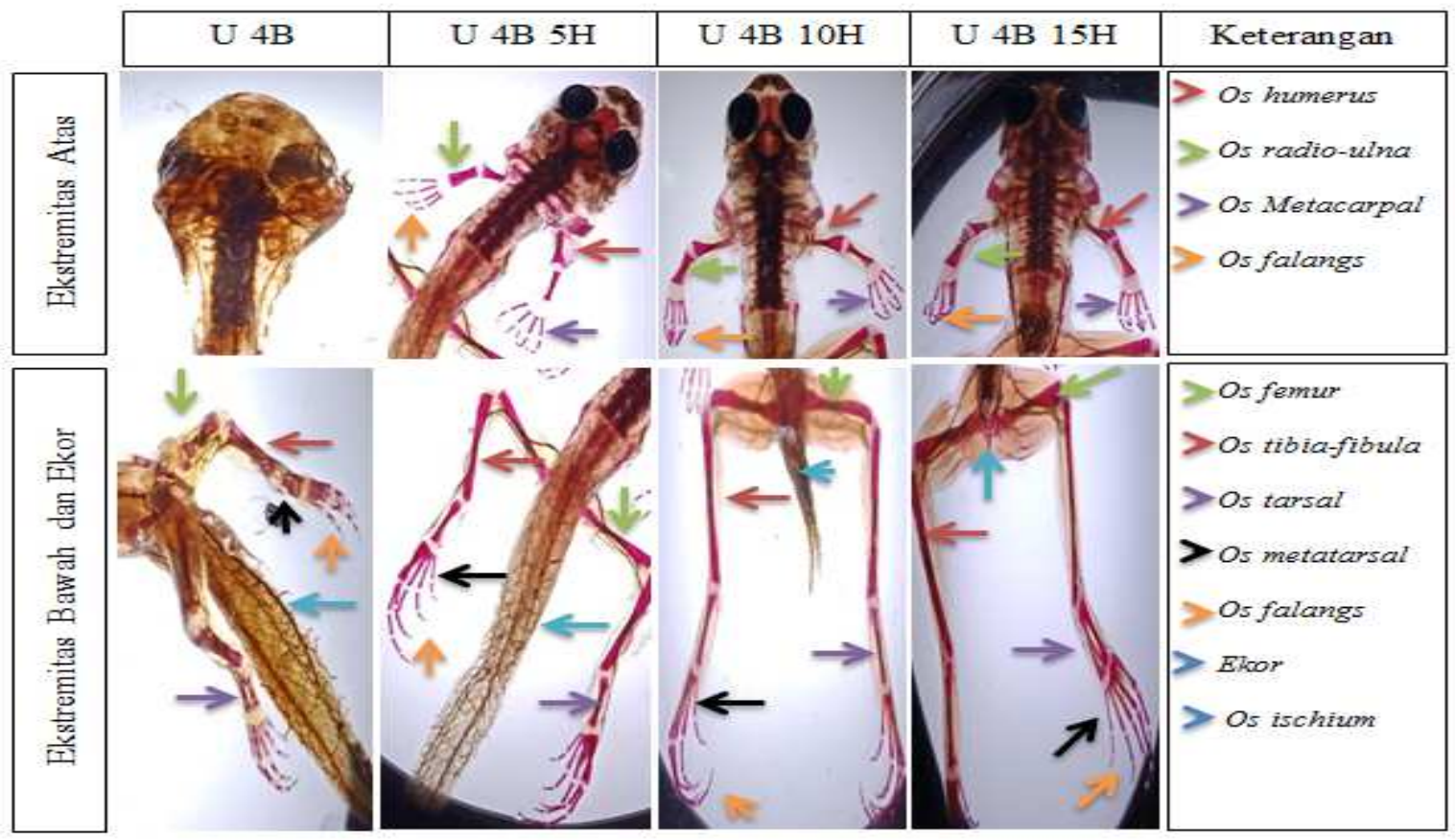

Keterangan
$\mathrm{U} 4 \mathrm{~B}$
: Usia 4 bulan
$\mathrm{U} 4 \mathrm{~B} 5 \mathrm{H}$
: Usia 4 bulan 5 hari
$\mathrm{U} 4 \mathrm{~B} 10 \mathrm{H}$
: Usia 4 bulan 10 hari
$\mathrm{U} 4 \mathrm{~B} 15 \mathrm{H}$
: Usia 4 bulan 15 hari

Gambar 2. Tulang pada Ekstremitas atas, Eksremitas posterior dan Ekor pada Berudu katak Rana catebeiana Shaw yang terwarnai Alizarin Red. 
e-Jurnal Ilmiah BIOSAINTROPIS (BIOSCIENCE-TROPIC)

Volume 5/ No.: 2 / Halaman 52 - 58 / Januari Tahun 2020

ISSN :2460-9455 (e) - 2338-2805(p)

Warna yang terdapat pada tulang menunjukkan tulang tersebut telah mengalami osifikasi, tulang yang terdapat pada ekstremitas anterior diantaranya os humerus, os radio-ulna, os carpal dan os falang yang terdapat pada masing-masing digiti.

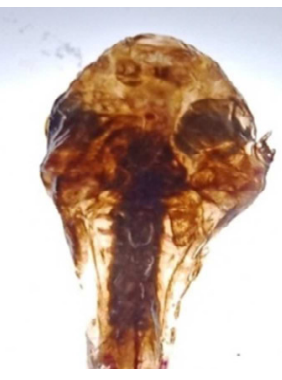

$\mathbf{a}$

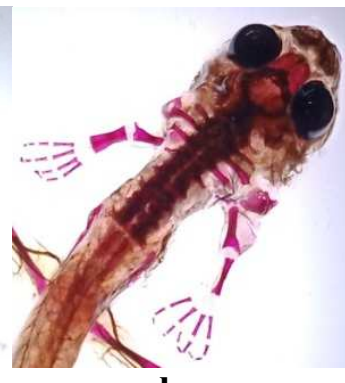

b

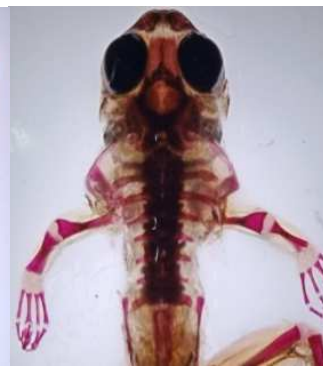

c

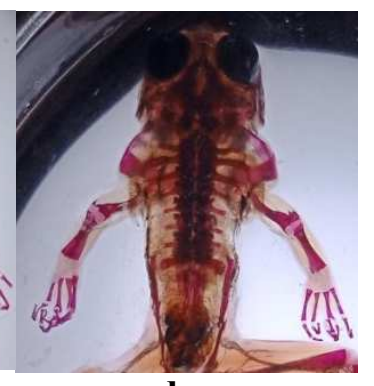

d

Gambar 2. Ekstremitas Atas Berudu Katak Rana catesbeiana Shaw usia a. 4 bulan, b. 4 bulan 5 hari, c. 4 bulan 10 hari dan d. 4 bulan 15 hari. Menggunakan Mikroskop Stereo (Perbesaran 8).

Tulang yang telah terwarnai tersebut selanjutnya dilakukan pengukuran dengan menggunakan jangka sorong.

Tabel 1. Rerata Panjang tulang pada Ekstremitas Atas Berudu Katak Rana catesbeiana Shaw. Berdasarkan hasil Pewarnaan dengan Alizarin red (X $\pm \mathrm{SD})$

\begin{tabular}{|c|c|c|c|c|}
\hline Metacarpal & $\mathrm{U} 4 \mathrm{~B}$ & $\mathrm{U} 4 \mathrm{~B} 5 \mathrm{H}$ & $\mathrm{U} 4 \mathrm{~B} 10 \mathrm{H}$ & $\mathrm{U} 4 \mathrm{~B} 15 \mathrm{H}$ \\
\hline Digiti 1 & $0 \pm 1,31$ & $1,05 \pm 1,31$ & $2,75 \pm 1,31$ & $2,6 \pm 1,31$ \\
\hline Digiti 2 & $0 \pm 1,30$ & $1,2 \pm 1,30$ & $2,75 \pm 1,30$ & $2,6 \pm 1,30$ \\
\hline Digiti 3 & $0 \pm 1,30$ & $1,2 \pm 1,30$ & $2,75 \pm 1,30$ & $2,6 \pm 1,30$ \\
\hline Digiti 4 & $0 \pm 1,30$ & $1,2 \pm 1,30$ & $2,75 \pm 1,30$ & $2,6 \pm 1,30$ \\
\hline Carpal & $0 \pm 0,00$ & $0 \pm 0,00$ & $0 \pm 0,00$ & $0 \pm 0,00$ \\
\hline Humerus & $0 \pm 2,46$ & $3,7 \pm 2,46$ & $5,3 \pm 2,46$ & $5,1 \pm 2,46$ \\
\hline Radio-Ulna & $0 \pm 2,46$ & $2,45 \pm 2,46$ & $3,6 \pm 2,46$ & $3,45 \pm 2,46$ \\
\hline $\begin{array}{l}\text { ngan } \\
\text { U 4B } \\
\text { U 4B 5H } \\
\text { U 4B 10H } \\
\text { U 4B } 15 \mathrm{H}\end{array}$ & $\begin{array}{l}\text { ia } 4 \text { bulan } \\
\text { ia } 4 \text { bulan } 5 \\
\text { ia } 4 \text { bulan } 1 \\
\text { ia } 4 \text { bulan } 1\end{array}$ & & & \\
\hline
\end{tabular}

Dari hasil pewarnaan yang telah dilakukan dilihat tulang apa saja yang telah mengalami osifikasi. Pada usia 4 bulan, ekstremitas atas belum mengalami osifikasi, terlihat dari hasil pengamatan dibawah mikroskop bahwa tdak ada tulang yang terwarnai. mengalami osifikasi. Pada usia 4 bulan, ekstremitas atas belum mengalami osifikasi, terlihat dari hasil pengamatan dibawah mikroskop bahwa tdak ada tulang yang terwarnai. Pada usia 4 bulan 5 hari, dari hasil pewarnaan dan pengamatan dibawah mikroskop terlihat telah mengalami osifikasi ditandai dengan tulang yang terwarnai menjadi merah tua, 
e-Jurnal Ilmiah BIOSAINTROPIS (BIOSCIENCE-TROPIC)

Volume 5/ No.: 2 / Halaman 52 - 58 / Januari Tahun 2020

ISSN :2460-9455 (e) - 2338-2805(p)

tulang yang telah mengalami osifikasi diantaranya os suprascapula, os humerus, os radio ulna, os metacarpal dan os falang. Berudu usia 4 bulan 10 hari juga telah mengalami osifikasi pada ekstremitas atas diantaranya os suprascapula, os humerus, os radio ulna, os metacarpal dan os falang yang terus memanjang seiring bertambahnya usia berudu begitu juga dengan berudu katak usia 4 bulan 15 hari yang terus mengalami pemanjangan pada tulang-tulang yang telah mengalami osifikasi.

Fase larva pada katak terdiri atas 21 tahapan. Kaki belakang (ekstremitas atas) mulai terbentuk pada tahap ke 26-30 dan terus mengalami pertumbuhan pada jari kaki belakang pada tahap ke 31-40.

Tabel 2. Rerata Panjang tulang pada Eksremitas posterior Berudu Katak Rana catesbeiana Shaw. Berdasarkan hasil Pewarnaan dengan Alizarin red

\begin{tabular}{crrrr}
\hline Metatarsal & \multicolumn{1}{c}{$\begin{array}{c}\text { U 4B } \\
(\mathrm{mm})\end{array}$} & \multicolumn{1}{c}{$\begin{array}{c}\mathrm{U} \text { 4B 5H } \\
(\mathrm{mm})\end{array}$} & \multicolumn{1}{c}{$\begin{array}{c}\mathrm{U} 4 \mathrm{~B} 10 \mathrm{H} \\
(\mathrm{mm})\end{array}$} & \multicolumn{1}{c}{$\begin{array}{c}\text { U 4B 15H } \\
(\mathrm{mm})\end{array}$} \\
\hline Digiti 1 & $0,8 \pm 1,05$ & $1,8 \pm 1,05$ & $2,65 \pm 1,05$ & $3,2 \pm 1,05$ \\
Digiti 2 & $1,55 \pm 1,26$ & $2,7 \pm 1,26$ & $4,2 \pm 1,26$ & $4,1 \pm 1,26$ \\
Digiti 3 & $1,65 \pm 1,55$ & $2,75 \pm 1,55$ & $4,8 \pm 1,55$ & $4,75 \pm 1,55$ \\
Digiti 4 & $2 \pm 1,41$ & $3,25 \pm 1,41$ & $4,8 \pm 1,41$ & $5 \pm 1,41$ \\
Digiti 5 & $2,1 \pm 1,17$ & $3,25 \pm 1,17$ & $4,5 \pm 1,17$ & $4,55 \pm 1,17$ \\
Tarsal & $2,15 \pm 1,52$ & $3,3 \pm 1,52$ & $4,6 \pm 1,52$ & $5,65 \pm 1,52$ \\
\hline Femur & $4,45 \pm 3,75$ & $8,75 \pm 3,75$ & $11,45 \pm 3,75$ & $13 \pm 3,75$ \\
Tibio-Fibula & $4,65 \pm 3,56$ & $8,3 \pm 3,56$ & $11,75 \pm 3,56$ & $12,35 \pm 3,56$ \\
\hline
\end{tabular}

Tabel 3. Pengamatan Ekor Pada Ekstremitas Atas Berudu Katak Rana catesbeiana Shaw. Berdasarkan hasil Pewarnaan dengan Alizarin Red-s

U 4B

U 4B 5H U 4B 10H U 4B 15H

\begin{tabular}{llrrrr}
\hline Ekor & Ischium & 0 & 0 & 1,1 & 1,8 \\
& $\begin{array}{l}\text { Panjang } \\
\text { Ekor }\end{array}$ & 44,65 & 39,2 & 11,55 & 2,7 \\
\hline
\end{tabular}

Keterangan

$\begin{array}{ll}\text { U 4B } & \text { : Usia } 4 \text { bulan } \\ \text { U 4B 5H } & \text { : Usia } 4 \text { bulan } 5 \text { hari } \\ \text { U 4B 10H } & \text { : Usia } 4 \text { bulan } 10 \text { hari } \\ \text { U 4B 15H } & \text { : Usia } 4 \text { bulan } 15 \text { hari }\end{array}$

\section{Pembahasan}

Tempat tumpuan ekstremitas anterior berupa cingulum cranialis (pectoral gride) yang berbentuk sebagai rangka yang melingkari alat-alat dalam thorax.Cingulum cranialis ini melekat pada vertebrae dengan otot daging.Masing-masing setengahnya terdiri atas tulang rawan lebar. Supra scapula sebelah dorsal, scapula kecil setelah lateral dan clavicula yang silindris dan coracoid yang lebar sebelah ventral yang terakhir ini bergabung dengan sternum yang berupa tulang rawan besar, tersusun atas episternum, omosternum, mesosternum dan xiphisternum. Pada sternum bertemulah os scapula dan 
caracoid, dan terbentuk mangkokan cavitas glenoidalis yang merupakan sendi tempat kepala os humerus [5].

Lengan atas atau Tulang humerus berupa tulang besar dan panjang, bersendi dengan scapula dibagian pada superior dan dibagian pada inferior bersendi pada ulna dan radius. Tulang radius terdapat di sebelah lateral, sedangkan os ulna di sebelah medialnya. Tulang radius dapat mengecil pada siku dan dapat juga membesar di pergelangan, tulang ulna berbanding terbalik dengan tulang radius.Pergelangan tangan di sokong dengan os carpal yang berjumlah 8 tulang yang disusun dalam dua barisan. Sementara tulang metacarpal berjumlah 4 tulang dapat menyokong bagian telapak tangan (digiti).Sedangkan 4 jari di sokong masing-masing dengan hanya 3 ruas jari atau falang, kecuali pada ibu jari yang di sokong dengan 2 buah ibu jari falang [6].

Tumpuan ekstremitas posterior yaitu cingulum posterior (pelvic girdle) adalah persatuan tulang yang memiliki bentuk, yang terdiri dari osillium disebelah anterior,os ischium disebelah posterior dan os pubis disebelah ventral. Tempat pada ketiga tulang bertemu terdapat seperti sebuah mangkok yang di sebut dengan acetabulum os femur melekat merupakan bertempat di kepala.Tiap-tiap bagian dari sepasang os illium yang merupakan tulang yang memanjang sejajar dengan urostyle dan bersenyawa dengan os vertebrae ke 9 (sacrum) [5].

Dari hasil tersebut terlihat perbedaan dari panjangnya ekstremitas atas dengan mulai memendeknya ekor pada berudu katak Rana catesbeiana Shaw.hal ini berkaitan dengan proses biokimia yang terjadi pada proses metamorfosis yaitu adanya peran hormon tiroid. Pada dasarnya ekor tidak mengalami degenerasi sampai terbentuk dan berkembangnya organ-organ lokomosi, seperti berkembangnya ekstremitas atas dan ekstremitas bawah untuk pergerakan.Kelenjar tiroid mulai berfungsi pada 10 hari setelah fase pembuahan, TH (Tyroid hormone) mengontrol satu jenis sel, yang mempengaruhi sel-sel lain pada anggota gerak. Pada proses ini kecebong berganti dari tipe ekor perenang kemudian menyelesaikan proses metamorfosisnya dengan menyerap ekornya [7]. Hormon paratiroid $(\mathrm{PTH})$ menstimulasi osteoklas untuk melepaskan kalsium dan fosfat dari tulang sehingga meningkatkan resorbsi tulang [8].

\section{Kesimpulan}

Kesimpulan pada penelitian ini adalah perkembangan tulang (osifikasi) yang terjadi pada berudu katak Rana catesbeiana Shaw usia 4 bulan, usia 4 bulan 5 hari, usia 4 bulan 10 hari, usia 4 bulan 15 hari dilihat dari pertambahan tulang pada masing-masing berudu dan bertambahnya panjang tulang yang mengalami kalsifikasi. Sistem lokomosi pada fase berudu katak masih berbentuk sirip yang membantu dalam pergerakan diair, dan terus mengalami pertumbuhan ekstremitas anterior yang diikuti dengan penyusutan ekor. Memendeknya ekor pada berudu dipengaruhi oleh hormon tiroid yang berperan penting pada proses metamorfosis serta kalsifikasi kalsium yang terdapat pada ekor berudu.

\section{Ucapan Terima Kasih}

Peternak peternak katak lembu Rana catesbeiana Shaw yang telah membantu dalam penyediaan bahan.

\section{Daftar Pustaka}

[1] IUCN. 2006. Conservation International and Nature Serve. Global Amphibian Assessment. Akses pada tanggal 22 Januari 2019. URL:http://www.globalamphibians.org.

[2] Muhadyanto, A. 1997. Pemijahan Katak Lembu. Balai Pengkajian Teknologi Pertanian Karangploso Instalasi Penelitian dan Pengkajian Teknologi Pertanian. Wonocolo

[3] Nugroho, A.E. dan Kazutaka, M. 2011. Evaluasi Pewarnaan Alcian Blue Terhadap Sel Mast Jaringan Ikat dari Preparat Beku Jaringan Kulit Kaki Tikus. Jurnal Pharmacy, Vol. 06 No. 01. Agustus 2011 (ISSN 1693-3591). 
e-Jurnal Ilmiah BIOSAINTROPIS (BIOSCIENCE-TROPIC)

Volume 5/ No.: 2 / Halaman 52 - 58 / Januari Tahun 2020

ISSN :2460-9455 (e) - 2338-2805(p)

[4] Puspitasari, D. 2015. Kunyit (Curcuma domestica Val.) Sebagai Pewarna Alternatif Pewarnaan Tulang Embrio Ayam (Gallus-gallus). Jurnal Bioedu (Berkala Ilmiah Pendidikan Biologi) Vol.4 No.1. Januari

[5] Jasir, M. 1984. Sistematik Hewan (Invertebrata dan Vertebrata). Cetakan ke-1. Sinar Wijaya. Surabaya.

[6] Saefudin. 2010. Rangka Manusia dan Hewan. Akses tanggal 25 Januari 2019. URL:http://file.upi.edu/Direktori/SPS/PRODI.PENDIDIKAN_IPA/196307011988031SAEFUDIN/Rangka_manusia_dan_hewan.pdf

[7] Brown, D.D., Liquan C, Biswajit. D, Nicholas. M, Armstrong, Alexander.M. Schreiber and Rejeanne Juste. 2005. Thyroid hormone controls multiple independent programs required for limb development in Xenopus laevis metamorphosis. PNAS Vol. 102 No.35 (www.pnas.org_cgi_doi_10.1073_pnas.0505989102 2005.

[8] Spear, PA., 2009. Study Design, Water Quality, Morphometrics and Ageof The Bullfrog, Rana catesbeiana, in Subwatersheds of The Yamaska River Drainage basin, Quebec, Canada. $J$. Aquatic Toxicology 91: 110-117. 